8-6-2015

\title{
Cumulative Risk and Teacher Well-Being in the Democratic Republic of the Congo
}

\author{
Sharon Wolf \\ University of Pennsylvania,wolfs@upenn.edu \\ Catalina Torrente \\ Yale University \\ Marissa McCoy \\ Yale University \\ Damira Rasheed \\ Fordham University \\ J. Lawrence Aber \\ New York University
}

Follow this and additional works at: https://repository.upenn.edu/gse_pubs

Part of the Community Psychology Commons, Education Policy Commons, International and Comparative Education Commons, and the Teacher Education and Professional Development Commons

\section{Recommended Citation}

Wolf, S., Torrente, C., McCoy, M., Rasheed, D., \& Aber, J. L. (2015). Cumulative Risk and Teacher Well-Being in the Democratic Republic of the Congo. Comparative Education Review, 59 (4), 717-742.

http://dx.doi.org/10.1086/682902

This paper is posted at ScholarlyCommons. https://repository.upenn.edu/gse_pubs/566

For more information, please contact repository@pobox.upenn.edu. 


\title{
Cumulative Risk and Teacher Well-Being in the Democratic Republic of the Congo
}

\begin{abstract}
Remarkably little systematic research has examined the living and working conditions for teachers in subSaharan Africa and how such conditions predict teacher well-being. This study assesses how various risks across several domains of teachers' lives-measured as a cumulative risk index-predict motivation, burnout, and job dissatisfaction in the Katanga province of the Democratic Republic of the Congo. Cumulative risk is related to lower motivation and higher burnout levels, and the relationship between cumulative risk and burnout is moderated by years of teaching experience. Specifically, less experienced teachers report the highest levels of burnout regardless of their level of cumulative risk. Experienced teachers with the low cumulative risk scores report the lowest levels of burnout, and burnout increases with higher levels of cumulative risk, suggesting that burnout decreases with experience but not for teachers who experience more risk factors. Implications for research and education policy in low-income and conflict-affected countries are discussed.
\end{abstract}

\section{Keywords}

cumulative risk, teacher well-being, Congo, teacher burnout, conflict, Central Africa

Disciplines

Community Psychology | Education | Education Policy | International and Comparative Education | Teacher Education and Professional Development 


\title{
Cumulative Risk and Teacher Well-Being in the Democratic Republic of the Congo
}

\author{
SHARON WOLF, CATALINA TORRENTE, MARISSA MCCOY, \\ DAMIRA RASHEED, AND J. LAWRENCE ABER
}

\begin{abstract}
Remarkably little systematic research has examined the living and working conditions for teachers in sub-Saharan Africa and how such conditions predict teacher well-being. This study assesses how various risks across several domains of teachers' lives-measured as a cumulative risk index - predict motivation, burnout, and job dissatisfaction in the Katanga province of the Democratic Republic of the Congo. Cumulative risk is related to lower motivation and higher burnout levels, and the relationship between cumulative risk and burnout is moderated by years of teaching experience. Specifically, less experienced teachers report the highest levels of burnout regardless of their level of cumulative risk. Experienced teachers with the low cumulative risk scores report the lowest levels of burnout, and burnout increases with higher levels of cumulative risk, suggesting that burnout decreases with experience but not for teachers who experience more risk factors. Implications for research and education policy in low-income and conflict-affected countries are discussed.
\end{abstract}

\section{Introduction}

There is growing concern that teachers in low-income countries are increasingly demotivated, which may partially explain deteriorating teaching performance and student learning outcomes, high rates of turnover and absenteeism, and misconduct (Moon 2006, 2007; Bennell and Akyeampong 2007). Importantly, teachers in low-income countries (LICs) are often ill equipped for the challenges of teaching and face many hardships in their work and personal lives that threaten their well-being and effectiveness in the classroom. Among the many challenges are increasing workloads due to education reform, low and infrequent compensation, lack of professional recognition and development opportunities, lack of accountability, and lack of voice (Bennell and Akyeampong 2007; Guajardo 2011; VSO 2002). Such problems may be particularly acute in conflict-affected countries, where limited resources coupled with historic and/or endemic violence can severely affect teaching conditions. While some have coined the present state of teachers in LICs as a "motivation crisis" (Moon 2007), more context-specific research

Received June 17, 2014; revised December 18, 2014; accepted April 1, 2015; electronically published August 6, 2015

Comparative Education Review, vol. 59, no. 4.

(C) 2015 by the Comparative and International Education Society. All rights reserved. 0010-4086/2015/5904-0003\$10.00 
is needed to understand how the conditions of teachers' work and personal lives affect their well-being and motivation.

Increasing teacher motivation and capabilities in the classroom is of central importance to the current set of international education goals, particularly in low-income and conflict-affected countries (CACs) where teachers face a unique set of challenges in and out of their work lives. Basic research on the predictors of teacher well-being and performance is critically needed to improve efforts to support teachers and inform policy decisions about how to most effectively allocate resources. As LICs and CACs work to improve educational quality, addressing the various hardships teachers face could be a critical policy lever. A first step is to better understand the realities of teachers' lives and how they relate to motivation and job well-being.

The present study uses a cumulative risk framework to examine the multiple challenges teachers experience and selected indices of their well-being. By surveying a representative sample of primary school teachers from the southeastern province of Katanga in the Democratic Republic of the Congo (DRC), this study explores the various risks teachers face in their lives in and out of work, as well as how these risks accumulate and relate to professional well-being. The three dimensions of the broader domain of well-being examined include motivation, referring to underlying psychological processes that influence individual behavior regarding workplace goals and tasks (Pinder 2008); burnout, conceptualized as a psychological syndrome in response to chronic work stressors (Maslach et al. 2001); and job dissatisfaction, which has been found to be one of the primary reasons for teachers leaving the profession (Green-Reese et al. 1992).

\section{Predictors of Teacher Well-Being in High-Income Countries}

Teaching is a stressful profession. In comparison with other professions, teachers show high levels of exhaustion and cynicism (Maslach et al. 1996; Schaufeli and Enzmann 1998), and up to one-fifth of teachers in the United States report being burned out at any given time (Borg and Riding 1991; Travers and Cooper 1996). Burned-out teachers can create harmful learning environments that are associated with negative outcomes for students. High levels of distress can lead to teacher burnout and deteriorating teacher performance (Osher et al. 2007; Tsouloupas et al. 2010), as well as poorer classroom climate (La Paro et al. 2009). Furthermore, teachers who are burned out and have low motivation are also shown to have lower self-efficacy about their abilities to teach (Friedman and Farber 1992).

The literature on teacher well-being from the United States shows that multiple aspects of teachers' lives are related to their motivation, burnout, and job satisfaction, including individual and school characteristics. Positive outcomes such as teacher motivation and job satisfaction have generally been 
linked with the fulfillment of intrinsic factors such as working with children, while negative outcomes such as job dissatisfaction and burnout have been found to be associated with extrinsic factors such as poor pay, work overload, and deterioration of the status of the teaching profession (IIEP 2004; see Spear et al. 2000 for a comprehensive review). In a summary of the literature on job burnout, Mashlach et al. (2001) explain that several work-related factors predict higher burnout rates, including high job demands with few job resources, lack of information, and lack of autonomy within the workplace. Several individual factors have also been consistently shown to predict burnout, though these associations are smaller in magnitude than those with work-related issues. Such individual factors include a lack of social support (related to teachers specifically; Kahn et al. 2006), age (with younger, less experienced employees showing higher rates; related to teachers specifically; Klassen and Chiu 2010), and marital status (with unmarried individuals showing the highest rates). These findings suggest that the challenges teachers face in their lives in and out of work can affect them negatively in the classroom.

Cross-cultural research in low- and middle-income countries such as South Africa, Iran, India, and Jordan suggests that determinants of teacher burnout are similar to those in the United States (Mohammadi et al. 2009). Systematic research on teacher well-being has been conducted outside the United States, but primarily in other high-income countries such as France, Germany, and the United Kingdom. Chang (2009) argued that in order to frame teacher burnout, the inherent cultural beliefs or economic development of different countries or cultures must first be examined. For example, a cross-cultural study compared Israeli and American teachers' stress and burnout levels and found Israeli teachers reported more stress related to larger class sizes, longer work hours, less administrative support, fewer resources, and exposure to dangerous environments than American teachers. However, despite the experience of more stressors, Israeli teachers reported lower burnout than American teachers (Pines 2002). This finding was explicated by further examination of the inherent cultural beliefs among Israelis. One belief that stood out was that Israeli teachers had a greater sense of importance and value in serving as a teacher than American teachers. Similar research is needed on teachers in low-income and conflict-affected countries, where many teachers lack proper training and face challenges in multiple arenas of their lives.

\section{Teaching in Low-Income and Conflict-Affected Countries Represents Special Challenges for Teachers}

Teachers in LICs and CACs face a unique set of barriers that require more basic research in order to fully understand. Relative to research in highincome conflict-free countries, much less systematic work has focused on 
teacher motivation and well-being in LICs and CACs as rigorous data are lacking. Teachers in LICs (regardless of being affected by conflict) increasingly face overcrowded classrooms due to the success of Education for All and the education-related Millennium Development Goals in increasing school enrollment, coupled with little increase in the teacher workforce (Hillman and Jenkner 2004).

Theoretical and empirical literature on teacher motivation in the developing world is scarce. One of the most systematic attempts to understand these issues empirically was summarized in a report of interviews and surveys with 10-20 key education stakeholders from 12 countries in sub-Saharan Africa and South Asia (Bennell and Akyeampong 2007). The report found that a sizable proportion of primary school teachers - over one-third-had low levels of job satisfaction and were poorly motivated, and that in subSaharan Africa there was a presence of chronically low motivation. The report concluded that there were many conditions that related to the current motivation "crisis" among teachers. The primary conditions included $(a)$ a cultural lack of accountability to schools, parents, and children; $(b)$ concern over safety and security resulting from war and conflict; $(c)$ overcrowded classrooms resulting from the universal primary education policies that have not been accompanied by increased resources for teachers; $(d)$ poor and unreliable compensation for work; $(e)$ deteriorating occupational status of the teaching profession; $(f)$ poor work and living conditions; and finally $(g)$ poor school and teacher management. A theoretical review and situational analysis of teacher well-being in developing countries found similar results (Guajardo 2011).

Specifically in low-income and conflict-affected countries such as the DRC, teachers not only experience risks associated with poverty, but are more likely to have experienced war-related trauma themselves and are often dealing with the aftermath of the conflict in their personal lives. In addition, schools may not only have few resources, but may also be located in high-conflict areas with low resources that can pose strains on teachers, students, and their interactions. In such contexts, individuals can be handpicked to become teachers in times of emergency, while having no teaching background or aspiration to become a teacher (Winthrop and Kirk 2005). Thus, different teachers may need a range of varied support such as improved work conditions and content and pedagogical knowledge training in order to be effective teachers (Kirk and Winthrop 2008). Teachers in these settings may lack confidence in their ability levels, feel self-conscious about their role as teachers, and feel like they are in an unfavorable and temporary profession (Kirk and Winthrop 2007, 2008).

These studies show that there are many factors and potential levers of change that need to be understood and targeted to improve teacher wellbeing in low-income countries. Understanding how various hardships may 
accumulate to overwhelm and affect teachers' abilities to support learning in the classroom is critical.

The Context: Recent History and Education in the Democratic Republic of the Congo

The DRC, the second largest country in the African continent, has the second lowest human development index in the world and has been afflicted by periods of violent conflict for the past 3 decades. Two successive and complex wars ravaged the country between 1996 and 2003, with renewed clashes in 2008 through the present day. In 2010, 1.7 million citizens were displaced, half of which were children (UNHCR 2010). Despite the country's abundant natural resources, the DRC ranks among the poorest countries in the world. Over the years, due to lack of financial resources, ongoing conflict and civil war, and large-scale internal displacement of citizens, education has been underfunded and underdeveloped (UNICEF 2013). The combination of dramatically low levels of social and economic development and ongoing political and social instability has ranked the DRC in the bottom 10 countries on the Global Peace Index (Institute for Economics and Peace 2014). The province of Katanga, where this study took place, was stable during the time of the study but has since become increasingly insecure with the resurgence of armed groups in some areas. While there was relative stability at the time of data collection, we still consider the area and the sample conflict-affected. The reverberations of armed conflict affect everyone directly or indirectly, and it is likely that most teachers in the sample were directly affected at one point in their lives. Thus, even in times of relative stability, it is difficult to disentangle the lasting consequences of ongoing armed conflict.

Fragile economic and security situations have negative effects on the development of the education system. In states whose governing structures have been weakened by conflict, populations necessarily rely on more localized governance. In the case of the DRC, as a result of insufficient public funding in previous years, household resources have played a large role in sustaining the education system, and teacher salaries are among the lowest in sub-Saharan Africa. Teachers living in poor and disadvantaged communities are often unable to lift themselves above the poverty line and are likely to seek additional jobs or relocate to communities with more resources (UNESCO 2014).

Though student enrollment continues to expand throughout the country due in part to community, religious, and private investments, approximately 29 percent of school-age children are not in school (UNICEF 2013). Within the DRC, significant variation in school enrollment exists. Compared to national averages, children in the eastern and southern provinces are less likely to be enrolled in primary school and are more likely to be orphaned or otherwise vulnerable (UNICEF and the Government of DRC 2008). Once 
children are enrolled in school, problems in educational quality persist, even in times of relative stability. A recent study of children (in the same schools as the sample of teachers in this study) in a southeastern province of the DRC found that 91 percent of primary-school children in grades 2-4 could not correctly respond to a single reading comprehension question on a test designed specifically for use in low- and middle-income countries (Torrente et al. 2011). Teachers' well-being may play a role in the observed low learning rates. In a sample of over 400 teachers in the same provinces, 25 percent reported going to bed hungry up to one-third of the time, and in a qualitative case study with 26 teachers, approximately one-third reported not feeling like a true teacher (Torrente et al. 2012; Frisoli 2013).

Despite the challenges, recent years have shown some positive signs for the country's economic stability and resource allocation for the social sector. The DRG has experienced economic progress in recent years with a growth in GDP over 7 percent and a decline in the inflation rate to below 10 percent (UNICEF 2013). In 2011, the government doubled the amount of money going to education from 6.5 to 13.8 percent of the national budget (Ackerman et al. 2013). Notably, efforts to improve educational access and quality are beginning to highlight the centrality of teacher well-being as a precursor for larger education improvement efforts. In a UNICEF report on out-ofschool children, education stakeholders highlight inadequate and irregular payment of teacher salaries and lack of training for some teachers as having a negative impact on educational quality and contributing to children's exclusion from school (UNICEF 2013). In addition, the government's Intermediary Education Plan released in 2012 identified teacher demotivation as a major challenge to reforms of the education system. The Prime Minister also recently declared that improving teacher training and teacher living standards was a top priority and recognized its important role in improving education in the DRC (UNESCO 2014). When recent professional development activities have been offered to teachers in the DRC, high participation and engagement rates are recorded, indicating that teachers are eager to improve their skills when offered the opportunity (EDC 2013; Frisoli 2013).

\section{A Cumulative Risk Approach to Understanding Teacher Well-Being} in the Democratic Republic of the Congo

A risk factor is defined as any individual or environmental factor associated with an increased likelihood of developing a negative or undesirable outcome (Kraemer et al. 2005). Research in child development has found that children who experience a single risk often do not fare more poorly than their peers. However, children who experience multiple risks are much more likely to be diagnosed with a psychological disorder (Rutter 1979, 1983; Sameroff 1989). A cumulative risk approach posits that no one risk factor is necessarily more harmful than another based on its content. Rather, it is the 
accumulation of risk, or the combination of exposure to multiple stressors, that overwhelms human adaptive capacities. If interrelated risk factors are simply manifestations of the same underlying construct (such as poverty, or in the case of teachers in the DRC, poor working conditions), then additional risks would not necessarily result in incrementally poorer outcomes. However, if risks are independent and cumulative, then together they would increase risk additively or exponentially. And in fact, multiple studies have shown that in studying the development of children at risk, prediction of adverse developmental outcomes is enhanced by the inclusion of multiple risks over a single risk factor (e.g., Lengua 2002; Evans 2003; Evans et al. 2013).

Toxic stress is one explanation for how and why cumulative risks may overwhelm teachers' capacities and "get under the skin" to affect well-being and disrupt their abilities to effectively interact with and teach in the classroom. The physiological response to stress is well defined and understood. Some stress is positive, and with supportive relationships is necessary to promote growth and development. What has come to bear more recently is what happens when the body must respond to stress for prolonged periods of time, and without the buffering protection of positive social support. This type of stress - known as toxic stress - is understood to be detrimental for human development and results from strong, frequent, or prolonged activation of the body's stress response systems (Shonkoff et al. 2012).

In this article, we draw upon the concept of cumulative risk from the child development literature to frame our analysis of the well-being of teachers in the DRC. A range of risk factors in teachers' work and personal lives that include both subjective and objective constructs are examined as elements of a cumulative risk index to predict teacher motivation and job well-being. Because this line of inquiry is extended to a new conceptual area of research, two follow-up questions are examined. The first considers if any particular domains of cumulative risk are more or less associated with teacher wellbeing (i.e., cumulative risk indices in five distinct domains of teachers' lives, including household hardship, health and well-being, social isolation, and subjective and objective work-related risks). The second, in line with previous research on teacher job burnout and satisfaction (e.g., Greenglass and Burke 1988; Mashlach et al. 2001; Brewer and Shapard 2004; Klassen and Chiu 2010), examines whether the relationship between cumulative risk and well-being differs for male versus female teachers, and for teachers with more versus less teaching experience.

Because the DRG is such a disadvantaged country in the midst of many years of violent conflict, our approach is to examine between-teacher variation in cumulative risk within this high-risk population. While the DRC has shown some positive signs of economic growth and stability in recent years, the country is widely held to be a failed state (Foreign Policy and the Fund for 
Peace 2010). Thus, while variation will exist in teachers' exposure to type and quantity of risks based on personal and community characteristics, all results should be considered testing the influence of "relative risk" on teacher wellbeing within this sample.

\section{The Present Study}

The overarching goals of this article are to $(a)$ contribute to theory and knowledge about how risk factors influence teacher motivation and wellbeing in understudied and challenging educational contexts, and $(b)$ thereby contribute to efforts to improve teacher capacities, especially in low-income countries affected by conflict. This article addresses the following research questions:

1. Is cumulative risk associated with lower teacher motivation and higher burnout and job dissatisfaction in a representative sample of primary school teachers from a southeastern province in the Democratic Republic of the Congo?

2. Are particular domains of cumulative risk more or less predictive of teacher motivation, burnout, and job dissatisfaction? In particular, are work-related risks more predictive than risks in the domains of teachers' personal lives?

3. Is the relationship between cumulative risk and teacher motivation, burnout, and job dissatisfaction different for male versus female teachers, and for teachers with more versus fewer years of teaching experience?

Method

Sample

Data for the current study come from a 2-year, three-wave impact evaluation of a teacher development program implemented in three eastern and southeastern provinces of the DRC: Katanga, South Kivu, and North Kivu. The program-which combines collaborative teacher learning circles and curricula for "Learning to Read in a Healing Classroom" and "Learning Math in a Healing Classroom" - is a part of "Opportunities for Equitable Access to Quality Basic Education,” a larger 5-year project aimed at improving teachers' motivation and performance, and elementary-school children's numeracy, literacy, and socio-emotional well-being. The project is implemented in a partnership between the International Rescue Committee (IRC), New York University, and the Ministry of Primary, Secondary, and Professional Education (MEPSP) in the DRC (see Author 2011 for details on the intervention and evaluation).

The impact evaluation employed a cluster-randomized, wait-list control design. This means that school clusters (i.e., geographically defined groups 
of 2-6 schools) were the unit of randomization, as opposed to schools, students, or teachers. Public lotteries were conducted whereby clusters were randomized to starting the intervention in each of three successive academic years: 2011, 2012, or 2013.

This article uses baseline data collected in 2011 in the province of Katanga. Eighty-four schools were randomly selected to participate in data collection from a total of 203 eligible schools grouped in 54 clusters. Eligible primary schools were officially registered government schools, were in a secure zone (e.g., no recent or current movement of armed groups), had at least four classrooms, were located in close proximity to other schools (i.e., within approximately 10 kilometers), were accessible by motorbike, and presumably not receiving similar supports by other education stakeholders. School size ranged widely from 78 students in sparsely populated rural areas to 1,240 students in more densely populated peri-urban areas. Schools were representative of the population of Katanga schools that met the criteria listed. All schools were underresourced, with varying amounts of support from the local community (Torrente et al. 2011).

A sample of 456 teachers was randomly selected within primary schools and represented all grades taught (1st through 6th). On average, teachers were 37.9 years old and had 12.5 years of teaching experience. The majority of teachers were male ( 71.7 percent), and the vast majority (96.6 percent) had completed at least some secondary school. Teachers spoke a variety of languages as their mother tongue, including Kiswahili (30.3 percent), Kiswahili and other (18.6 percent), Kibemba (12.4 percent), Kisanga (11.7 percent), Kiluba (6.0 percent), Tshokwe (4.9 percent), French (2.0 percent), and other (14.2 percent). All teachers in the sample were intended to receive payment for their work, and almost all (97.5 percent) reported receiving some salary.

\section{Procedure}

Teachers were asked to answer a survey about their educational background, livelihoods, and feelings and perceptions about their job and teaching experiences. Consent was requested from all teachers at the time of data collection, and field staff reported a compliance rate of 100 percent. The maximum time allotted for each interview was 90 minutes. Teacher surveys were conducted in French (the official language of instruction in DRC) by local staff trained in data collection procedures by the research team.

\section{Measures}

All measures were translated from English into French and back translated by IRC field research staff to ensure cultural and conceptual equivalence to the original survey. All scale items were developed based on previous literature and were initially vetted with Congolese education and monitoring 


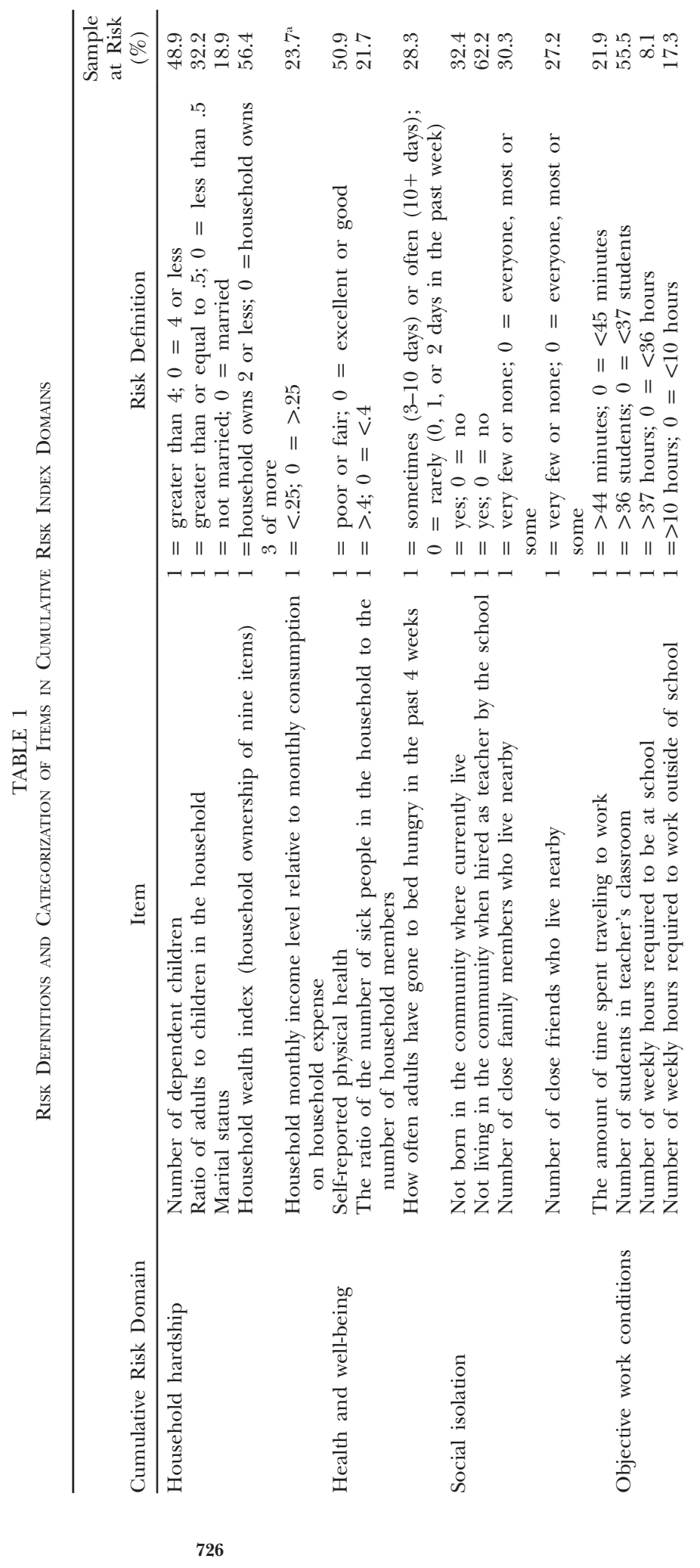




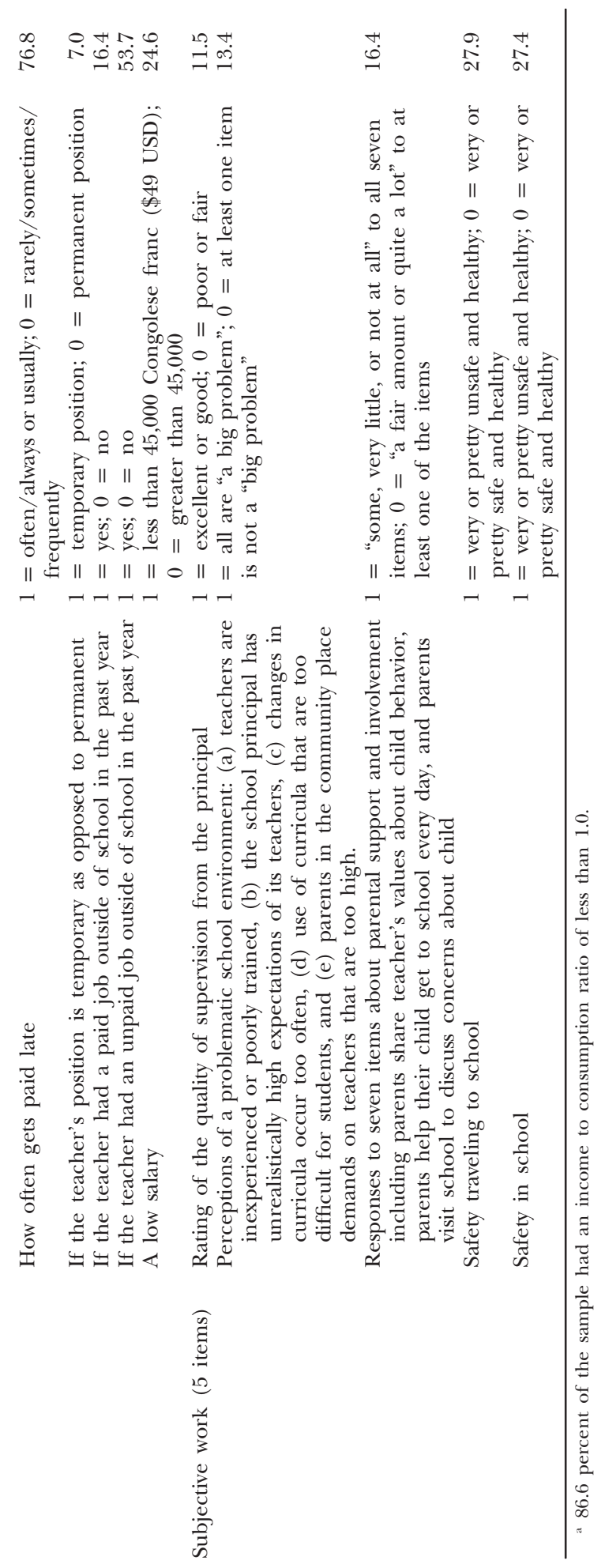


and evaluation staff to ensure that the constructs meanings reflected cultural nuances. In addition, all items were piloted with a group of 30 teachers before their inclusion in the survey. After teachers filled out the surveys in the pilot testing, descriptive analyses on each of the items were conducted to eliminate items that were unclear or that did not show any variation.

\section{Cumulative Risk Index}

In order to create a cumulative risk index, each risk factor was defined dichotomously as present or absent $(1 / 0)$ on the basis of statistical or theoretical criteria, or based in previous research (Michaelowa 2001; Bennell and Akyeampong 2007). Cumulative risk was defined as the simple, unweighted sum of each of the risk factors within and across categories based on cumulative risk theory of human development (described above; Evans et al. 2013). Table 1 describes how risk was defined for each item. Teachers' scores on all dichotomous risk factors were summed to create a cumulative risk index. The maximum score possible was 26 (see fig. 1 for a distribution of the cumulative risk index).

\section{Domains of Risk}

In addition to creating an overall cumulative risk index, the index was divided into five separate cumulative risk indices. Each index represents a domain of teachers' working and living conditions in order to assess whether risks in particular areas of teachers' lives were more or less detri-

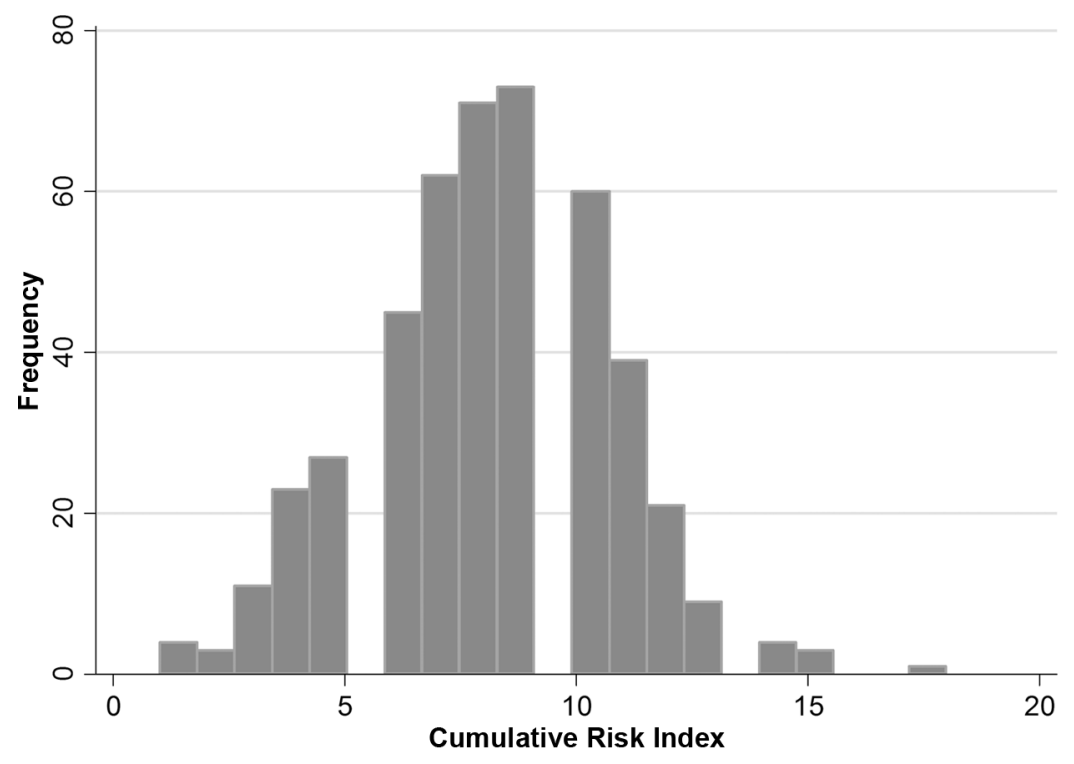

FIG. 1.-Distribution of cumulative risk index 
mental to their well-being. The face-valid domains are also based in previous research of teacher well-being, as well as material hardship and adult well-being more broadly. Table 1 describes how items were categorized by domains.

We consider work-related risks, which include objective conditions, shown to be related to teacher morale and motivation (Bennell and Akyeampong 2007), as well as subjective work conditions, shown to be positively related to job burnout in the US literature (Mashlach et al. 2001). In addition, we consider elements of non-work-related living conditions shown to be important components of material hardship and adult well-being. These include household hardship, health and well-being of individual and household members, and degree of social isolation (Corcoran et al. 1999; Bauman 2003; Heflin et al. 2009).

\section{Teacher Motivation}

Nine items were used to measure teachers' motivation and were developed by the researchers based on work by Bennell and Akyeampong (2007). Items asked teachers to rate on a scale of 0 ("completely false") to 3 ("completely true") their level of agreement with a set of statements such as "I'm highly motivated to help children learn to read and write" and "I'm highly motivated to help children develop well socially" $(\alpha=.80)$.

\section{Teacher Burnout}

Nine items were used to measure teachers' burnout and were taken from the Maslach Burnout Inventory (Maslach et al. 1996) designed to assess educational populations. The items were taken from two subscales-emotional exhaustion (a chronic state of physical and emotional depletion) and depersonalization (feeling disconnected and lacking of control) - that were combined. Items asked teachers to use a scale from 0 ("never") to 6 ("every day") to indicate, for instance, how often they have felt "mentally drained from their work" or "fatigued when they wake up in the morning" $(\alpha=.73)$.

\section{Job Dissatisfaction}

Four items were used to measure teachers' level of dissatisfaction with their job. The items were developed by the researchers based on work by Bennell and Akyeampong (2007). Teachers were asked to use a scale of 1 ("completely true") to 4 ("completely false") to rate how true the statements were about themselves and about other teachers in the school. Statements were "I want to transfer to another school," "I want to leave the teaching profession," "Other teachers want to transfer to another school," and "Other teachers want to leave the teaching profession" $(\alpha=.72)$.

Covariates

Covariates were included in all models and included teacher gender $(1=$ female; 28.3 percent), grade taught ( 1 st grade $=16$ percent, 2 nd grade $=19$ 
percent, 3rd grade $=18$ percent, 4 th grade $=19$ percent, 5 th grade $=14$ percent, and 6 th grade $=13$ percent), language spoken (Kiswahili as mother tongue $=48.9$ percent $)$; teacher's age $(M=37.9, \mathrm{SD}=13.1$; range $=17.9-$ $74.9)$, years of teaching experience $(M=12.7$, $\mathrm{SD}=12.6$, range $=0.1-54.0)$, and parent education $(0=$ did not complete any schooling, 15.1 percent; $1=$ completed primary education, 34.7 percent; and $2=$ completed secondary education or higher, 50.2 percent; notably, only 4 percent of the sample had parents who completed any education higher than a secondary degree). In addition, we included an indicator for whether there was more than one school sampled within a school cluster (representing large administrative districts), and a dummy indicator for each of the six subdivisions.

\section{Analytic Plan}

Three-level hierarchical linear models (teachers nested in schools nested in school clusters) were used to estimate the relationship between cumulative risk and teacher's motivation, burnout, and job dissatisfaction. One primary model was estimated for each teacher outcome, which assessed the relationship between total cumulative risk and each outcome. In addition, three follow-up analyses were conducted: $(a)$ the cumulative risk index was split into five indices representing specific domains of cumulative risk to assess whether any particular domains of cumulative risk were more or less strongly associated with teacher well-being, and interaction terms were included in the primary model to assess moderation of risk and well-being by $(b)$ teacher gender and $(c)$ years of teaching experience. Each model included all covariates.

Missing data were minimal. On average, items were missing data at a rate of only 0.8 percent. As a result, we used listwise deletion, resulting in the loss of 7-11 cases (1-2 percent of the sample) depending on the model.

\section{Results}

Descriptive Statistics

Descriptive statistics and intercorrelations are presented in table 2. On average, teachers experienced 8.2 risks of the 26 possible risks $(\mathrm{SD}=2.6$ ). There were small correlations among the different categories of cumulative risk indices (.00-.19), and moderate-size correlations between each category and total number of risks (.46-.50).

Table 3 displays the intraclass correlations (ICCs) for all cumulative risk indices and teacher outcomes. ICCs are estimates of the proportion of variance that is attributable to differences between teachers, schools, and school clusters. The results indicate that the majority of the variance in cumulative risk was explained by differences across teachers themselves (67-86 percent) rather than differences across schools or school clusters. Notably, schools 
CUMULATIVE RISK AND TEACHER WELL-BEING IN THE DRC

TABLE 2

Descriptive Statistics and Intercorrelations of Cumulative Risk Indices and Teacher Outcomes

\begin{tabular}{|c|c|c|c|c|c|c|c|c|c|c|c|c|}
\hline & M & $\mathrm{SD}$ & Min & Max & 1 & 2 & 3 & 4 & 5 & 6 & 7 & 8 \\
\hline \multicolumn{13}{|l|}{ Cumulative risk indices: } \\
\hline 1. Cumulative risk & 8.15 & 2.58 & 1.00 & 18.00 & 1.00 & & & & & & & \\
\hline 2. Household & & & & & & & & & & & & \\
\hline hardship risk & 1.79 & .98 & .00 & 4.00 & .50 & 1.00 & & & & & & \\
\hline 3. Health and & & & & & & & & & & & & \\
\hline well-being risk & 1.02 & .85 & .00 & 3.00 & .47 & .19 & 1.00 & & & & & \\
\hline 4. Social isolation risk & 1.84 & 1.29 & .00 & 5.00 & .44 & .00 & .00 & 1.00 & & & & \\
\hline 5. Objective work & & & & & & & & & & & & \\
\hline conditions risk & 2.60 & 1.07 & .00 & 6.00 & .50 & .14 & .08 & -.12 & 1.00 & & & \\
\hline 6. Subjective work & & & & & & & & & & & & \\
\hline conditions risk & .98 & 1.06 & .00 & 5.00 & .46 & -.01 & .07 & -.06 & .14 & 1.00 & & \\
\hline \multicolumn{13}{|l|}{ Outcomes: } \\
\hline 7. Motivation & 2.49 & .52 & .78 & 3.00 & -.20 & -.06 & -.14 & -.11 & -.04 & -.15 & 1.00 & \\
\hline 8. Burnout & 2.76 & 1.29 & .00 & 6.00 & .19 & .06 & .19 & .05 & .05 & .15 & -.13 & 1.00 \\
\hline 9. Job dissatisfaction & 1.95 & 1.08 & 1.00 & 4.00 & .00 & -.06 & -.04 & .07 & -.05 & .03 & -.15 & .04 \\
\hline
\end{tabular}

Note.-Correlations that are bold are statistically significant at $P<.05$.

explained a larger share of variance in the categories of objective work risks (28 percent), subjective work risks (20 percent), and total risks (23 percent), and a smaller share of variance in risks pertaining to teacher's personal lives such as household risks (2 percent) and health and well-being risks ( 1 percent). The majority of variance for teacher motivation, burnout, and job dissatisfaction was due to differences in teachers themselves $(74,79$, and 76 percent, respectively). Differences due to schools were largest for job dissatisfaction (24 percent) compared to motivation and burnout ( 4 and 8 percent, respectively).

\section{Multivariate Results}

The results of our main analyses of the influence of risk on teacher outcomes are reported in table 4 . The first column in each panel in table 4

TABLE 3

Intraclass Correlations of Cumulative Risk Indices and Teacher Outcomes

\begin{tabular}{lccc}
\hline & \multicolumn{3}{c}{ Proportion of Variance } \\
\cline { 2 - 4 } & Teacher & School & Cluster \\
\hline Cumulative risk indices: & .750 & .226 & .024 \\
Cumulative risk & .832 & .024 & .144 \\
Household hardship risk & .863 & .012 & .125 \\
Health and well-being risk & .709 & .111 & .180 \\
Social isolation risk & .670 & .281 & .049 \\
Objective work conditions risk & .798 & .202 & .000 \\
Subjective work conditions risk & & & .219 \\
Teacher well-being: & .738 & .044 & .125 \\
Motivation & .791 & .084 & .000 \\
Burnout & .763 & .237 & \\
Job dissatisfaction & & & \\
\hline
\end{tabular}


WOLF ET AL.

TABLE 4

Coefficient Estimates from Three-Level Models Assessing the Relationship between Cumulative Risk and Teacher Motivation, Burnout, and Job Dissatisfaction

\begin{tabular}{|c|c|c|c|c|c|c|}
\hline & \multicolumn{2}{|c|}{ Motivation } & \multicolumn{2}{|c|}{ Burnout } & \multicolumn{2}{|c|}{ Job Dissatisfaction } \\
\hline & Model 1 & Model 2 & Model 1 & Model 2 & Model 1 & Model 2 \\
\hline Gender $(1=$ female $)$ & .043 & .049 & -.145 & -.169 & $.228 *$ & $.227 *$ \\
\hline Grade & -.007 & -.005 & .038 & .033 & .024 & .023 \\
\hline Kiswahili is mother tongue & -.016 & -.018 & .037 & .049 & .036 & .044 \\
\hline Age & .005 & .005 & -.001 & .001 & -.007 & -.008 \\
\hline Parent education & -.001 & .000 & .085 & .088 & .051 & .046 \\
\hline Years of experience & -.003 & -.003 & .004 & .002 & -.002 & -.003 \\
\hline Cumulative risk: & $-.032 * * *$ & & $.068 * *$ & & .021 & \\
\hline Household hardship risk & & -.027 & & .022 & & .003 \\
\hline Health and well-being risk & & -.038 & & $.258 * * *$ & & -.031 \\
\hline Social isolation risk & & $-.037^{+}$ & & .046 & & .061 \\
\hline $\begin{array}{l}\text { Objective work conditions } \\
\text { risk }\end{array}$ & & .007 & & -.006 & & -.010 \\
\hline $\begin{array}{l}\text { Subjective work conditions } \\
\text { risk }\end{array}$ & & $-.071 * *$ & & $.112 *$ & & .061 \\
\hline Variance components: & & & & & & \\
\hline Teacher & .199 & .198 & 1.301 & 1.250 & .852 & .851 \\
\hline School & .014 & .012 & .125 & .147 & .236 & .228 \\
\hline Cluster & .025 & .024 & .000 & .000 & .000 & .000 \\
\hline Sample size $($ total $=456)$ & 448 & 448 & 449 & 449 & 445 & 445 \\
\hline
\end{tabular}

(i.e., model 1) shows the relationship between teacher's cumulative risk index score and motivation, burnout, and job dissatisfaction. Results from this model show that there is a statistically significant and negative relationship between cumulative risk and motivation $(b=-.032, P<.001)$ and a positive relationship with burnout $(b=.068, P<.01)$, but no statistically detectable relationship between cumulative risk and job dissatisfaction. Results indicate that each additional risk is associated with lower teacher motivation and burnout by a magnitude of 5-6 percent of a standard deviation.

As suggested by Evans et al. (2013), we also assessed nonlinear forms of the relationship between cumulative risk and teacher well-being by adding $(a)$ a squared term of the cumulative risk index, and $(b)$ a squared and a cubed term of the cumulative risk index. None of these terms were statistically significant for any of the three outcomes, leading us to conclude that the relationship observed between cumulative risk and teacher well-being is linear.

The second column in each panel in table 4 (i.e., model 2) separates the cumulative risk index into five separate domains of risk and shows the relationship between these specific domains and teacher outcomes. For motivation, shown in the first panel, results show that only each additional risk in the domain of subjective work conditions was statistically significantly associated with lower teacher motivation $(b=-.071, P<.01)$, and each ad- 
ditional risk in the domain of social isolation was marginally statistically significantly associated with lower teacher motivation $(b=-.037, P<.06)$. While other categories showed a negative association with teacher motivation, no coefficients were statistically significant. For teacher burnout, shown in the second panel, results show that each additional risk in the domain of health and well-being was positively and statistically significantly associated with burnout $(b=.258, P<.001)$, as was each additional risk in the domain of subjective work conditions $(b=.112, P<.05)$. Finally, as with the cumulative risk index, no specific domains of risk were statistically significantly associated with teacher job dissatisfaction.

\section{Moderation in the Relationship between Cumulative Risk and Teacher Well-Being by Gender and Years of Teaching Experience}

Building on model 1, the moderation analyses shown in table 5 examined whether there were differences in the relationship between cumulative risk and teacher well-being by two policy and practice relevant teacher characteristics: gender and years of teaching experience. We found statistical significance for one interaction term out of the six tested. Specifically, the relationship between cumulative risk and burnout was moderated by the number of years of teaching experience $(b=.004, P<.05)$. Figure 2 displays the relationship graphically and indicates that regardless of levels of cumulative risk, less experienced teachers report high levels of burnout. In contrast, there is a strong relationship between cumulative risk and burnout for teachers with higher levels of experience. Simple slope computations show that this relationship is statistically significant for teachers with average levels of experience $(b=.072, P<.01)$ and for teachers with high levels of experience $(b=.123, P<.001)$.

\section{Discussion}

While it is well understood that teachers are critical agents of change in improving school quality, few of the current international initiatives formally

TABLE 5

Coefficient Estimates from Three-Level Interaction Models of Cumulative Risk with Gender and with Years of Experience

\begin{tabular}{lcccrrr}
\hline & \multicolumn{2}{c}{ Motivation } & \multicolumn{2}{c}{ Burnout } & \multicolumn{2}{c}{ Job Dissatisfaction } \\
\hline Gender $(1=$ female $)$ & .040 & .043 & $-.714^{+}$ & -.187 & .021 & $.216^{+}$ \\
Years of experience & -.003 & -.003 & .003 & -.027 & -.003 & -.012 \\
Cumulative risk & $-.032^{* *}$ & $-.032^{* *}$ & $.048^{+}$ & .021 & .014 & .007 \\
Cumulative risk $\times$ gender & .004 & & .071 & & .026 & .001 \\
Cumulative risk $\times$ years of experience & & .000 & & $.004^{*}$ & & \\
\hline Nore.-Covariates not shown. Total years of teaching experience centered on the grand mean value for mod- \\
eration analysis. \\
$\quad+P<.10$. \\
$\quad * \quad P<.05$.
\end{tabular}




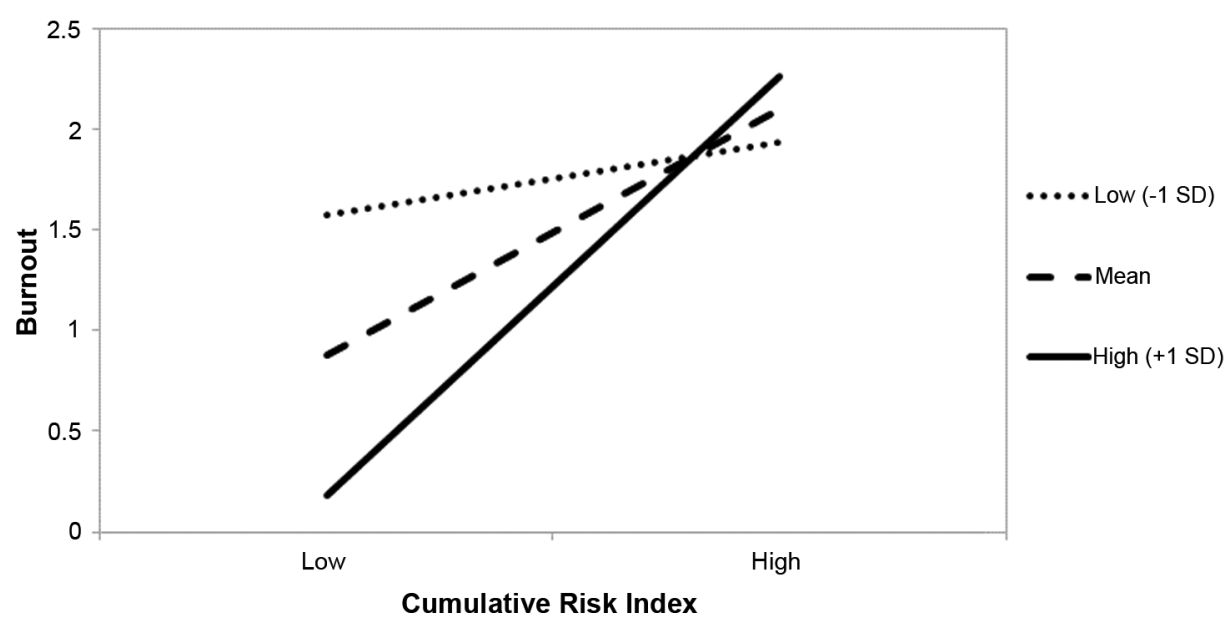

FIG. 2.-Moderation of cumulative risk, years of teaching experience, and burnout. NotE.-Slope of lines are statistically significant for teachers with mean years of teaching experience and with high years of teaching experience at levels of $P<.01$ and $P<.001$, respectively.

recognize the importance of improving teaching for achieving universal primary education and learning (Dlada and Moon 2012). There is a need for research to provide the foundation upon which such potential can be realized. This article presented one of the first studies to empirically assess the relationship between risk factors in teachers' lives - both in and out of workand three indices of teachers' well-being (motivation, burnout, and job dissatisfaction), which we anticipate are related to teaching performance in subSaharan Africa.

We find evidence of a small but meaningful linear relationship between higher cumulative risk with lower teacher motivation and higher burnout, but no relationship between cumulative risk and job dissatisfaction. Follow-up analyses revealed that higher levels of risk in teachers' subjective perceptions of their work environment were statistically significantly associated with both lower motivation and higher burnout. In addition, higher levels of one domain of personal risk, teachers' health and well-being, was statistically significantly associated only with higher burnout. And surprisingly, higher levels of risk in the domains of household risk, social isolation, and objective work conditions as reported by teachers did not predict teacher motivation, burnout, or job dissatisfaction.

The finding that teachers' motivation and burnout levels are related to their subjective work conditions but not objective work conditions is noteworthy. The measure of subjective work conditions includes reports of poorquality supervision from the principal, a problematic school environment, 
lack of parental support and involvement, and feeling unsafe traveling to school and while in school. The findings highlight the importance of the interactions teachers experience with other adults in their work environments in predicting motivation and burnout. These findings speak to research with female teachers in Afghanistan, suggesting that the opportunity to teach and participate in the community was an important motivation for quality teaching and learning (Kirk and Winthrop 2008). Similarly, work in the United States show that schools in which teachers report high levels of cooperation among school staff have the largest gains in student achievement over time (Lee and Smith 1996).

In addition, risks in the domain of health and well-being predicted teachers' burnout but not motivation or job dissatisfaction. This domain of cumulative risk included physical health, the proportion of sick people in the household, and how often adults go hungry in the home. Measures of food insufficiency have been linked to low-income adults' worse physical and mental health in the United States, including depression and sense of mastery (Siefert et al. 2004; Helfin et al. 2005). While teacher burnout contained items pertaining to job-related burnout, the items included feelings related to both depression and sense of mastery. Specifically, the emotional exhaustion subscale refers to exhaustion, fatigue, strain, and feeling mentally drained, while the depersonalization subscale refers to feelings of frustration, callousness, and becoming emotionally hardened. The findings indicate that personal health and food insufficiency contribute to teacher emotional exhaustion and depersonalization and are remarkably consistent with related research from the United States. These findings have implications for the consequences of the widespread low and infrequent remuneration of teachers.

Finally, we find evidence that the relationship between cumulative risk and burnout is moderated by years of teaching experience. Specifically, less experienced teachers report the highest levels of burnout regardless of their level of cumulative risk, while more experienced teachers report increased burnout with higher levels of cumulative risk. Highly experienced teachers with the lowest cumulative risk scores report the lowest levels of burnout, which suggests that burnout decreases as teachers become more experienced, but not for teachers who experience more risk factors in their lives. Furthermore, the finding that teachers with the least amount of experience report the highest levels of burnout is consistent with findings in Western contexts that show that younger and less experienced teachers have the highest rates of job burnout (Mashlach et al. 2001; Brewer and Shapard 2004).

The relationships observed between cumulative risk and teacher wellbeing were relatively small but practically meaningful. The main effects of cumulative risk indicate that each additional risk was associated with 5-6 per- 
cent of a standard deviation decrease in teacher motivation and increase in burnout. While this number is relatively small in magnitude, it indicates that experiencing eight risks (the mean for the sample) is associated with 40-50 percent of a standard reduction in motivation and burnout. This likely has implications for teaching performance and student learning. Importantly, the entire sample of teachers studied is at high risk, and thus the results indicate the relationship between "relative risk" and teacher well-being. For example, 85 percent of the sample experienced five or more risks. This withingroup nature of the analyses provides a context for the relatively small associations found.

\section{Limitations}

This study has several important limitations. First, all variables used in the analysis were self-reported by teachers and thus subject to mono-method bias (Donaldson and Vallone 2002). Consequently, our measure of cumulative risk is best understood as an index of teachers' perceptions of the conditions and hardships in their lives. While most of the risk factors relied on objective information (e.g., marital status, number of children and adults in the household, number of hours worked per week), they are still subject to any inaccuracies of self-report. Second, the sample of teachers in this study was one of comparatively high risk, and the within-group analysis limited the ability to detect a relationship between risk and well-being due to the relatively restricted range of risks experienced by teachers. Third, the high-risk nature of the sample, while highly relevant to teachers in conflict-affected countries, raises a limitation of generalizability of the findings to teachers in active conflict zones, and to low-income countries that have not experienced armed conflict. Future work could investigate similar research questions in a lower risk sample, potentially in a low-income country that has not faced the same amount of hardship and recent conflict as the DRC. Finally, none of the risk factors assessed were directly about violence and conflict exposure. This limits our ability to understand the unique context of the DRC as a conflict-affected country in addition to a low-income country. Future work could consider the effects of violence exposure relative to other types of risks associated with teaching in a low-resourced environment more generally.

\section{Implications}

Our results indicate that the cumulative hardships teachers face in their work and personal lives contribute to the poor motivation and burnout found in other studies (Chaudhury et al. 2006; Moon 2006; Bennell and Akyeampong 2007). It is critical that conditions for teachers, both professionally and personally, are targeted for improvement in order to enhance teachers' capabilities and effectiveness in the classroom. First, the findings in this study 
indicate that changing material work conditions, such as reducing class size or increasing access to textbooks, may not be the most effective first step to improving teacher well-being and thus, presumably, teacher performance. Rather, efforts to improve the nature of interactions among staff within a school, such as school management and supervision, may be more important at this stage. In addition, increasing the status of the teaching profession could improve teachers' subjective perceptions of their work conditions as well as their actual and perceived support from the community.

Second, while improving all of the conditions of teachers' work and personal lives is not possible, the linear relationship found between risk and wellbeing suggest the targeted efforts to reduce some of the difficulties would improve teacher well-being incrementally. If governments take steps to address individual challenges, the risk of teachers becoming "overwhelmed" by cumulative stress will decline. For example, the fact that personal health and food insufficiency contribute to higher levels of burnout indicate that teacher salaries - both level and timeliness of payment - is one incremental change that can be addressed. This type of administrative improvement is straightforward and a direct lever of change that policies can target.

Third, the findings that burnout levels are high among the least experienced teachers regardless of their cumulative risk level suggests that new teachers are at high risk of burnout irrespective of the work and personal hardships they face. This fact may contribute to the high rates of absenteeism and turnover in the profession (Chaudhury et al. 2006; Bennell and Akyeampong 2007). This suggests that in-service professional development programs for new teachers are critically needed. Such efforts may consider providing ongoing support and feedback to new teachers (e.g., Downer et al. 2011) during their first years in the profession as a way to reduce burnout and increase retention in the profession.

This study is timely for the DRC in light of the government's recent public identification of the need to improve teachers' working conditions, and of the recognition of teacher well-being as central to successfully reforming the education system (MEPSP 2012). High enthusiasm and participation rates in recent teacher professional development activities in the DRG (EDC 2013) indicate that teachers are eager to engage in such efforts. There is still a relative dearth of basic research to inform the most efficient and optimal ways to improve conditions for teachers. Some efforts to build this foundation of knowledge are currently underway. For example, the Teacher Education in sub-Saharan Africa (TESSA) has started an initiative to create a network of African universities and international organizations to focus on the education and training needs of teachers (Harley and Barasa 2012). But much more work is needed.

Next steps in research should include evaluating if and how schoolbased program or policy interventions reduce burnout and increase moti- 
vation, and what role cumulative risk may play in teachers effectively utilizing such programs. In addition, if programs do successfully improve teacher well-being, research is needed to examine whether those changes lead to improved teacher practices, classroom learning environments, and student learning outcomes as is hoped. Such research will enable a greater understanding of the mechanisms through which effective programs work, and will help to unpack if and how school-based interventions improve educational quality and student learning. Enhanced knowledge is crucial in order to design the most effective educational programs and policies.

In order for leaders to fulfill their promise of every child achieving a quality primary education, they must first make and fulfill promises to the teachers who educate these children. Overlooking teacher well-being will result in a crucial missed opportunity to improve child and human development.

\section{References}

Ackerman, X., L. Greubel, and R. Winthrop. 2013. "The New Push for Education Reform in the Democratic Republic of the Congo." Brookings Brief Up Front, March 1. http://www.brookings.edu/blogs/up-front/posts/2013/03/01 -education-reform-congo-winthrop.

Bauman, K. J. 2003. Extended Measures of Well-Being: Living Conditions in the United States: 1998. Washington, DC: US Census Bureau.

Bennell, P., and K. Akyeampong. 2007. Teacher Motivation in Sub-Saharan Africa and South Asia. London: DfID.

Borg, M. G., and R. J. Riding. 1991. "Stress in Teaching: A Study of Occupational Stress and Its Determinants, Job Satisfaction and Career Commitment among Primary School Teachers." Educational Psychology 11:59-76.

Brewer, E. W., and L. Shapard. 2004. "Employee Burnout: A Meta-analysis of the Relationship between Age or Years of Experience." Human Resource Development Review 3 (2): 102-23.

Chang, M.-L. 2009. "An Appraisal Perspective of Teacher Burnout: Examining the Emotional Work of Teachers." Educational Psychology Review 21 (3): 193-218.

Chaudhury, N., J. Hammer, M. Kremer, M. Karthik, and F. H. Rogers. 2006. "Missing in Action: Teacher and Health Worker Absence in Developing Countries." Journal of Economic Perspectives 20:91-116.

Corcoran, M. E., C. M. Heflin, and K. Siefert. 1999. "Food Insufficiency and Material Hardship in Post-TANF Welfare Families." Ohio State Law Review 60:1395-1422.

Dladla, N., and B. Moon. 2012. "Teachers and the Development Agenda: An Introduction." In Teacher Education and the Challenge of Development: A Global Analysis, ed. B. Moon. New York: Routledge.

Donaldson, S. I., and E. J. Grant-Vallone. 2002. "Understanding Self-Report Bias in Organizational Behavior Research." Journal of Business and Psychology 17 (2): 245-60.

Downer, J. T., R. C. Pianta, X. Fan, B. K. Hamre, A. Mashburn, and L. Justice. 2011. "Effects of Web-Mediated Teacher Professional Development on the Language 
and Literacy Skills of Children Enrolled in Prekindergarten Programs." NHSA Dialog: Research-to-Practice Journal for the Early Childhood Field 14:189-212.

EDC (Education Development Center). 2013. "Teachers Step Up for Better Education: In the Democratic Republic of Congo, Teacher Training Shows Promising Results."http://www.edc.org/newsroom/articles/teachers_step_better_education.

Evans, G. W. 2003. "A Multimethodological Analysis of Cumulative Risk and Allostatic Load among Rural Children.” Developmental Psychology 39 (5): 924-33.

Evans, G. W., D. Li, and S. S. Whipple. 2013. "Cumulative Risk and Child Development.” Psychological Bulletin 139 (6): 1342-96.

Foreign Policy and the Fund for Peace. 2010. "2010 Failed States Index." Foreign Policy, June 21. http://www.foreignpolicy.com/articles/2010/06/21/2010_failed _states_index_interactive_map_and_rankings.

Friedman, I. A., and B. A. Farber. 1992. "Professional Self-Concept as a Predictor of Teacher Burnout." Journal of Educational Research 86 (1): 28-35.

Frisoli, P. St. J. 2013. "Teachers' Experiences of Professional Development in (Post) Crisis Katanga Province, Southeastern Democratic Republic of Congo: A Case Study of Teacher Learning Circles." PhD diss., University of Massachusetts, Amherst.

Greenglass, E. R., and R. J. Burke. 1988. "Work and Family Precursors of Burnout in Teachers: Sex Differences." Sex Roles 18 (3-4): 215-29.

Green-Reese, S., D. Johnson, and W. Campbell. 1992. "Teacher Job Satisfaction and Teacher Job Stress: School Size, Age and Teaching Experience." Education 112:247-52.

Guajardo, J. 2011. Teacher Motivation: Theoretical Framework, Situation Analysis of Save the Children Country Offices and Recommended Strategies. Washington, DC: Save the Children.

Harley, K., and F. S. Barasa. 2012. "TESSA: Teacher Education in Sub-Saharan Africa." Formative Evaluation Report, Teacher Education in Sub-Saharan Africa, Milton Keynes.http://www.tessafrica.net/files/tessafrica/TESSA_Formative _Evaluation_Report_October_2012(1).pdf.

Heflin, C. M., J. Sandberg, and P. Rafail. 2009. "The Structure of Material Hardship in US Households: An Examination of the Coherence behind Common Measures of Well-Being." Social Problems 56 (4): 746-64.

Heflin, C. M., K. Siefert, and D. R. Williams. 2005. "Food Insufficiency and Women's Mental Health: Findings from a 3-Year Panel of Welfare Recipients." Social Science and Medicine 61 (9): 1971-82.

Hillman, A. L., and E. Jenkner. 2004. "Educating Children in Poor Countries." International Monetary Fund, Economic Issues, no. 33.

IIEP (International Institute for Education Planning). 2004. "Teachers: A Priority." IIEP Newsletter 22 (1).

Institute for Economics and Peace. 2014. Global Peace Index: Measuring and Assessing County Risk. New York: Institute for Economics and Peace. http://www .visionofhumanity.org/sites/default/files/2014\%20Global\%20Peace\%20Index \%20REPORT.pdf .

Kahn, J. H., K. T. Schneider, T. M. Jenkins-Henkelman, and L. L. Moyle. 2006. "Emotional Social Support and Job Burnout among High-School Teachers: Is It All Due to Dispositional Affectivity?” Journal of Organizational Behavior 27 (6): 793-807. 
Kirk, J., and R. Winthrop. 2007. "Promoting Quality Education in Refugee Contexts: Supporting Teacher Development in Northern Ethiopia." International Review of Education 53:715-23.

Kirk, J., and R. Winthrop. 2008. "Home-Based School Teachers in Afghanistan: Teaching for Tarbia and Student Well-Being." Teaching and Teacher Education 24 (4): 876-88.

Klassen, R. M., and M. M. Chiu. 2010. "Effects on Teachers' Self-Efficacy and Job Satisfaction: Teacher Gender, Years of Experience, and Job Stress." Journal of Educational Psychology 102 (3): 741-56.

Kraemer, H. C., K. K. Lowe, and D. J. Kupfer. 2005. To Your Health: How to Understand What Research Tells Us about Risk. London: Oxford University Press.

La Paro, K. M. L., B. K. Hamre, J. Locasale-Crouch, R. C. Pianta, D. Bryant, D. Early, et al. (2009). "Quality in Kindergarten Classrooms: Observational Evidence for the Need to Increase Children's Learning Opportunities in Early Education Classrooms." Early Education and Development 20:657-92.

Lee, V. E., and J. B. Smith. 1996. "Collective Responsibility for Learning and Its Effects on Gains in Achievement for Early Secondary School Students." American Journal of Education 104 (2): 103-47.

Lengua, L. J. 2002. "The Contribution of Emotionality and Self-Regulation to the Understanding of Children's Response to Multiple Risk." Child Development 73 (1): 144-61.

Maslach, C., S. E. Jackson, and M. P. Leiter. 1996. Maslach Burnout Inventory manual. 3rd ed. Palo Alto, CA: Consulting Psychologists Press.

Maslach, C., W. B. Schaufeli, and M. P. Leiter. 2001. "Job Burnout." Annual Review of Psychology 52 (1): 397-422.

MEPSP (Ministère de l'Enseignement Primaire, Secondaire et Professionnel). 2012. Plan intérimaire de l'éducation 2012-2014. Kinshasa: MEPSP.

Michaelowa, K. 2001. "Primary Education Quality in Francophone Sub-Saharan Africa: Determinants of Learning Achievement and Efficiency Considerations." World Development 29 (10): 1699-1716.

Mohammadi, S., E. Danesh, and B. R. Shejwal. 2009. "A Comparative Study of Coping Mechanisms and Job Burnout among Iranian and Indian High School Teachers." International Journal of Psychology 3:22-42.

Moon, B. 2006. Research Analysis: A Global Overview of Current Policies and Programmes for Teachers and Teacher Education. Paris: UNESCO.

Moon, B. 2007. "School-Based Teacher Development in Sub-Saharan Africa: Building a New Research Agenda." Curriculum Journal 18 (3): 355-71.

Osher, D., J. Sprague, R. P. Weissberg, J. Axelrod, S. Keenan, K. Kendziora, et al. 2007. "A Comprehensive Approach to Promoting Social, Emotional, and Academic Growth in Contemporary Schools." In Best Practices in School Psychology, ed. A. Thomas and J. Grimes, vol. 5, 5th ed. Bethesda, MD: National Association of School Psychologists.

Pinder, C. C. 2008. Work Motivation in Organizational Behavior. 2nd ed. New York: Psychology Press.

Pines, A. M. 2002. "Teacher Burnout: A Psychodynamic Existential Perspective." Teachers and Teaching: Theory and Practice 8:121-40. 
Rutter, M. 1979. "Protective Factors in Children's Responses to Stress and Disadvantage." Annals of the Academy of Medicine 8:324-38.

Rutter, M. 1983. "Stress, Coping, and Development." In Stress, Coping, and Development in Children, ed. N. Garmezy and M. Rutter. New York: McGraw-Hill.

Sameroff, A. 1989. "Models of Developmental Regulation: The Environtype." In The Emergence of Discipline, Rochester Symposium on Developmental Psychopathology, ed. D. Cicchetti. Vol. 1. Hillsdale, NJ: Erlbaum.

Schaufeli, W., and D. Enzmann. 1998. The Burnout Companion to Study and Practice: A Critical Analysis. London: CRC Press.

Shonkoff, J. P., A. S. Garner, B. S. Siegel, M. I. Dobbins, M. F. Earls, L. McGuinn, et al. 2012. "The Lifelong Effects of Early Childhood Adversity and Toxic Stress." Pediatrics 129:232-46.

Siefert, K., C. M. Heflin, M. E. Corcoran, and D. R. Williams. 2004. "Food Insufficiency and Physical and Mental Health in a Longitudinal Survey of Welfare Recipients." Journal of Health and Social Behavior 45 (2): 171-86.

Spear, M., K. Gould, and B. Lee. 2000. Who Would Be a Teacher? A Review of Factors Motivating and De-motivating Prospective and Practicing Teachers. London: National Foundation for Educational Research.

Torrente, C., J. L. Aber, A. Shivshanker, J. Annan, and T. Bundervoet. 2011. “Opportunities for Equitable Access to Quality Basic Education (OPEQ): Results from the Early Grade Reading Assessment, the Early Grade Math Assessment, and Children's Demographic Data in Katanga Province, Democratic Republic of Congo.” Report, New York University. http://steinhardt.nyu.edu/scmsAdmin/media/users /eez206/OPEQ/OPEQ_Baseline_Report_EGRA_EGMA_2011_FINAL.pdf.

Torrente, C., J. L. Aber, D. Witteveen, T. Gupta, B. Johnston, A. Shivshanker, J. Annan, and T. Bundervoet. 2012. "Baseline Report: Teacher Survey Results." Report, New York University. http://steinhardt.nyu.edu/scmsAdmin/media/users /eez206/OPEQ/OPEQ_Teacher_Survey_BL_Report_DRC_2012-08-14.pdf.

Travers, C. J., and C. L. Cooper. 1996. Teachers under Pressure: Stress in the Teaching Profession. London: Routledge.

Tsouloupas, C. N., R. L. Carson, R. Matthews, M. J. Grawitch, and L. K. Barber. 2010. "Exploring the Association between Teachers' Perceived Student Misbehaviour and Emotional Exhaustion: The Importance of Teacher Efficacy Beliefs and Emotion Regulation.” Educational Psychology 30:173-89.

UNESCO. 2014. "Education: The Democratic Republic of Congo in the Spotlight." Press review, UNESCO, May 28. http://www.newsfromafrica.org/newsfromafrica /articles/art_14220.html.

UNHCR (United Nations High Commissioner for Refugees). 2010. "Internally Displaced Persons (IDP) — Fact Sheet: Democratic Republic of Congo." UNHCR, Geneva, April.

UNICEF and the Government of DRC. 2008. Pauvrete des Enfants et Disparites en Republique Democratique du Congo. New York: UNICEF.http:/ / www.unicef.org/drcongo /french/RDC_Rapport_pauvrete.pdf.

UNICEF. 2013. Global Initiative for Out-of-School Children: Democratic Republic of Congo. New York: UNICEF. http://www.unicef.org/education/files/DRC_OOSCI _Full_Report_\%28En\%29.pdf. 
WOLF ET AL

VSO. 2002. "What Makes Teachers Tick? A Policy Research Report of Teacher's Motivation in Developing Countries." Report, VSO, London. http://www.vso.org.uk /Images/What_Makes_Teachers_Tick_tcm79-21000.pdf.

Winthrop, R., and J. Kirk. 2005. "Teacher Development and Student Well-Being." Forced Migration Review 22:18-21. 